\title{
Há uma horta no meio da cidade
}

There is a garden in the middle of the city

Hay una huerta en medio de la ciudad

Soler Gonzalez - Universidade Federal do Espírito Santo | PPGME/Ufes | Vitoria | ES | Brasil. E-mail: solergonzales2011@gmail.com

Andréia Teixeira Ramos - Faculdade Brasileira Multivix - Vitória | Multivix - Vitória | Vitoria |ES | Brasil. E-mail: andreiatramos.ea@gmail.com

Resumo: Este texto ressalta as perspectivas ecologistas das práticas pedagógicas realizadas em 2018 com as turmas de graduação em Pedagogia e Geografia, do Centro de Educação da Universidade Federal do Espírito Santo, permeadas por diálogos amorosos, estudos e problematizações de situações concretas que vivemos nos cotidianos como sujeitos históricos com capacidade de conhecer e intervir no mundo e com o mundo. Nosso desejo com este artigo é apresentar movimentos de aprender e ensinar, que fazem parte das concepções do Projeto Narradores da Maré, com ênfase nos movimentos ecologistas das práticas pedagógicas aqui expostas com narrativas e imagens. Nosso posicionamento se aproxima dos pensamentos de Paulo Freire e de Marcos Reigota conectados com as dimensões éticas, teóricas e metodológicas das perspectivas ecologistas de educação. Durante o semestre letivo criamos momentos de leituras, estudos e diálogos em sala de aula, oficinas de composteira, aulas de campo no centro histórico de Vitória e seminários de apresentação dos Grupos de Trabalhos.

Palavras-chave: Práticas pedagógicas. Perspectiva ecologista de educação. Narrativas.

Abstract: This text emphasizes the ecological perspectives of the pedagogical practices carried out in 2018 with the undergraduate courses in Pedagogy and Geography, of the Education Center of the Federal University of Espírito Santo, permeated by love dialogues, studies and problematizations of concrete situations that we live in daily life as subjects with the ability to know and intervene in the world and with the world. Our desire with this article is to present learning and teaching movements, which are part of the conceptions of the Tidal Storytellers Project, with an emphasis on the ecological movements of pedagogical practices presented here with narratives and images. Our positioning approaches the thoughts of Paulo Freire and Marcos Reigota connected with the ethical, theoretical and methodological dimensions of the ecology perspectives of education. During the semester, we created moments of reading, studies and dialogues in the classroom, composter workshops, field lessons in the historical center of Vitória and seminars to present the work groups.

Keywords: Pedagogical practices. Perspective education ecologist. Narratives.

Resumen: Este texto resalta las perspectivas ecologistas de las prácticas pedagógicas realizadas en 2018 con las turmas de grado en Pedagogía y Geografía, del Centro de Educación de la Universidad Federal de Espírito Santo, permeadas por diálogos amorosos, estudios y problematizaciones de situaciones concretas que vivimos en los cotidianos como sujetos históricos con capacidad de conocer e intervenir en el mundo y con el mundo. Nuestro deseo con este artículo es presentar movimientos de aprender y enseñar, que hacen parte de las concepciones del Proyecto Narradores da Maré, con énfasis en los movimientos ecologistas de las prácticas pedagógicas aquí expuestas con narrativas e imágenes. Nuestro posicionamiento se acerca a los pensamientos de Paulo Freire y de Marcos Reigota conectados con las dimensiones éticas, teóricas y metodológicas de las perspectivas ecologistas de educación. Durante el semestre lectivo creamos momentos de lecturas, estudios y diálogos en aula, talleres de compostaje, clases de campo en el centro histórico de Vitória y seminarios de presentación de los Grupos de Trabajos.

Palabras clave: Prácticas pedagógicas. Perspectiva ecologista de educación. Narrativas.

- Recebido em 12 janeiro de 2019 • Aprovado em 21 de março 2019 • e-ISSN: 2177-5796

DOI: http://dx.doi.org/10.22483/2177-5796.2019v21n1p157-178

Copyright @ 2019. Conteúdo de acesso aberto, distribuído sob os termos da Licença Internaonal da CreativeCommons - CC BY-NC-SA Atribuição Não Comercial (https://br.creativecommons.org/licencas/) - Permite distribuição e reprodução, desde que atribuam os devido créditos à publicação, ao autor(es) e que licenciem as novas criações sob termos idênticos. 


\section{Primeiras palavras}

Ensinar não é transferir conhecimento, mas criar possibilidades para a sua própria produção ou a sua construção (FREIRE, 1996, p. 22).

Este texto ressalta as perspectivas ecologistas das práticas pedagógicas realizadas com as turmas de graduação em Pedagogia e Geografia, do Centro de Educação (CE) da Universidade Federal do Espírito Santo (Ufes), permeadas por diálogos amorosos (FREIRE, 2014), estudos e problematizações de situações concretas que vivemos nos cotidianos como sujeitos históricos com "capacidade de, intervindo no mundo, conhecer o mundo" (FREIRE, 1996, p. 28).

Nosso desejo com este artigo é apresentar movimentos de aprender e ensinar, que fazem parte das concepções do Projeto Narradores da Maré ${ }^{1}$, com ênfase nas práticas pedagógicas realizadas com estudantes da Ufes em 2018, aqui expostas com narrativas (REIGOTA, 2016) e imagens. Nos pautamos nos pensamentos de Paulo Freire e de Marcos Reigota com base nas dimensões éticas, teóricas, políticas e metodológicas das perspectivas ecologistas de educação (BARCHI; REIGOTA; YANG, 2018; RAMOS, 2018), com isso, exercitamos a dimensão ética no fazer docente, pois:

A transgressão ética nos adverte de como urge que assumamos o dever de lutar pelos princípios éticos mais fundamentais como o respeito à vida dos seres humanos, à vida dos outros animais, à vida dos pássaros, à vida dos rios e das floretas. (FREIRE, 2014, p. 77).

Partindo dessa dimensão ética e ecológica freireana, gostaríamos de ressaltar nossa compreensão de uma ecologia que vai além do conceito de ecologia tradicional. Exercitamos "as noções contemporâneas de ecologia" dialogando com Marcos Reigota (1999b, p.19; 1998, 2012). Nesse contexto, para pensar a perspectiva ecologista de educação nos interessa aqui destacar também a educação ambiental como educação política que: "Está comprometida com a

${ }^{1}$ O Projeto de Extensão Narradores da Maré: geografias dos manguezais da Baía de Vitória e a formação de professores/as foi registrado na Pró-Reitoria de Extensão (Proex), da Universidade Federal do Espírito Santo, em 26/08/2014 com o $n^{\circ}$ 4.00927. O projeto também se desmembra em pesquisas de iniciação científica, de ensino, com orientações de trabalhos de conclusão de curso e dissertações de mestrado profissional em educação. Ressaltamos que as práticas pedagógicas aqui apresentadas são articuladas com o Grupo de Pesquisa "Territórios de Aprendizagens Autopoiéticas (CNPq)".

Quaestio, Sorocaba, SP, v. 21, n. 1, p. 157-178, jan./abr. 2019. 
ampliação da cidadania, da liberdade, da autonomia e da intervenção direta dos cidadãos e das cidadãs na busca de soluções e alternativas que permitam a convivência digna voltada para o bem comum" (REIGOTA, 2012, p. 13).

Em companhia dessa perspectiva apresentamos situações concretas cotidianas e pedagógicas de educação ambiental como educação política, entendendo que,

Essa perspectiva teórica e política enfatiza as práticas pedagógicas e sociais cotidianas que se identificam como educação ambiental, produzidas à margem e em contraposição à educação ambiental das políticas públicas, dos dispositivos de controle e de validação acadêmica e das biopolíticas (BARCHI; REIGOTA; YANG, 2018, p. 266).

Desse modo, exercitamos em nossas ações de ensino, pesquisa e extensão o comprometimento ético e político, de uma educação ambiental que "não está vinculada à transmissão de conhecimentos sobre a natureza, mas sim à possibilidade de ampliação de participação política dos cidadãos e cidadãs" (REIGOTA, 2012, p. 97). Com essa perspectiva buscamos criar espaços dialógicos, de convivências e de aprendizagens, com a intenção de nos afastarmos da concepção "bancária" de educação, "em que a única margem de ação que se oferece aos educandos é a de receberem os depósitos, guardá-los e arquivá-los. Margem para serem colecionadores ou fichadores das coisas que arquivam” (FREIRE, 2014, p. 80-81).

Em nosso fazer docente, ao nos inserirmos na luta contra as concepções bancárias de educação, pensamos com Paulo Freire (2014, p. 81) que "só existe saber na invenção, na reinvenção, na busca inquieta, impaciente, permanente, que os homens e as "mulheres" fazem no mundo, com o mundo e com os outros. Busca esperançosa também”.

Com isso, as práticas pedagógicas aqui apresentadas por meio de imagens e narrativas se enveredam pelos caminhos e movimentos das perspectivas ecologistas de educação, se desviando da educação "bancária" "para a qual a educação é o ato de depositar, de transferir, de transmitir valores e conhecimentos" (FREIRE, 2014, p. 82), reforçando a "cultura do silêncio" em sala de aula, onde o educador é que diz a palavra; e os educandos, os que a escutam docilmente.

Assim, desejamos com esse texto enfatizar nossas aproximações com as perspectivas ecologistas de educação, evidenciando também o quanto refutamos a "cultura do silêncio" no nosso fazer docente, ao exercitarmos diálogos amorosos em consonância com os pensamentos de Paulo Freire (2014), que ao dizer que o diálogo é fenômeno humano e uma exigência existencial, nos instiga na realização de práticas pedagógicas dialógicas amorosas, que movimentam e criam uma interação solidária entre os sujeitos da história (FREIRE, 1996), envolvidos nos processos de 
aprendizagens, com a vontade de transformar e agir criticamente no mundo. Assim, é necessário destacar que "não há diálogo, se não há um profundo amor ao mundo e aos homens e 'as mulheres'. Não é possível a pronúncia do mundo, que é um ato de criação e recriação, se não há amor que a infunda. Sendo fundamento do diálogo, o amor é, também, diálogo" (FREIRE, 2014, p. 110).

\section{Início de mais um ano letivo}

A alegria não chega apenas no encontro do achado mas faz parte do processo de busca. E ensinar e aprender não podem dar-se fora da procura, fora da boniteza e da alegria (FREIRE, 1996, p. 142).

O ano de 2018 começou com ares inquietantes, foi preciso ânimo para caminhar e conviver com as adversidades e "ruídos do mundo" (GUIMARÃES, 2016). Com essa vibração iniciamos o semestre com as ações do projeto Narradores da Maré e com graduandos e graduandas das disciplinas "Geografia: conteúdo e metodologia", ofertada ao sexto período do curso de Pedagogia, matutino e noturno, e, “Tópicos Especiais de Ensino I", ofertada ao terceiro período da licenciatura de Geografia-noturno, e que nos fazem resistir, criar e reinventar a vida e a educação.

Nesse contexto, para além dos Programas de Ensino e das ementas das disciplinas que possibilitaram diálogos de saberes com outras geografias, territorialidades e temporalidades, nossa intenção pedagógica durante os encontros foi de problematizar o potencial ético, político, pedagógico e ecológico das práticas pedagógicas e de narrativas compartilhadas com diálogos amorosos, escutas e com "a curiosidade como inquietação indagadora" (FREIRE, 1996, p. 32).

Durante o semestre letivo aproveitamos os momentos de leitura e estudos em sala de aula para nos aproximarmos das concepções teóricas, metodológicas, éticas e políticas das perspectivas ecologistas de educação, por meio de oficinas de composteira, aulas de campo no centro histórico de Vitória e seminários de apresentação dos Grupos de Trabalhos (GTs).

Diante de inúmeras possibilidades de leituras, optamos por artigos que dialogassem com as perspectivas ecologistas de educação, e os escolhidos foram: "Cidade, lugar do possível: experimentações para um ver a mais" (2014) e "Imagem e clichê: proposições para um ver a 
mais" (2015), de Larrisa Corrêa Firmino; "Geografia experimental do corpo ou de como se chega a dizer outra coisa da geografia, da terra, do mundo", de Danilo Stank Ribeiro, Raphaela Desidério e Ana Maria H. Preve (2013); e uma versão deste mesmo artigo intitulada "Paisageando na composição de paisagens sensacionais" de Danilo Stank Ribeiro (2015). Incluímos ainda "As perspectivas ecologistas em Educação e as hortas pedagógicas e orgânicas: a ação do PIBID Geografia da Uniso" (2017), de Rodrigo Barchi.

No decorrer dos debates e leituras dos artigos tivemos a possibilidade de assistir pequenos vídeos, músicas e poesias, numa atitude de professor e "pesquisador conversador" (SPINK, 2008), acrescentando outras indicações de leituras, com destaque para os livros "Ecologias inventivas: conversas sobre educação" (PREVE et al, 2012), "Ecologias inventivas: experiências das/nas paisagens" (GUIMARÃES et al, 2015)", o livro "Ecologistas" (REIGOTA, 1999a), as obras freireanas, "Pedagogia do Oprimido" (FREIRE, 2014), "Pedagogia da Autonomia" (FREIRE, 2009) e os "livros-dialogados" de Paulo Freire e Sérgio Guimarães, "Aprendendo com a própria história" (FREIRE; GUIMARÃES, 2011a) e "Dialogando com a própria história" (FREIRE; GUIMARÃES, 2011b).

\section{Oficinas de composteira}

Não haveria criatividade sem a curiosidade que nos move e que nos põe pacientemente impacientes diante do mundo que não fizemos, acrescentando a ela algo que fazemos (FREIRE, 1996, p. 32).

Foi numa quarta-feira à noite, na disciplina ministrada para a turma de Pedagogia, no calor das discussões e debates sobre "As perspectivas ecologistas em Educação e as hortas pedagógicas e orgânicas: a ação do PIBID Geografia da Uniso”, de Rodrigo Barchi (2017), que nos deparamos com práticas ecologistas de educação realizadas com o PIBID, e, dentre elas, compostagem, horta orgânica de verduras e legumes, e o plantio de milho e mandioca orgânico e não transgênico.

Durante os diálogos sobre o texto, uma graduanda comentou em sala de aula:

Professor, dá para fazer uma composteira usando uma garrafa pet. Eu vi com a professora que eu acompanho no estágio. A gente podia fazer aqui na sala de aula. 
A proposta foi prontamente endossada pela turma. Assim, iniciamos as pesquisas de modelos conhecidos e os materiais que seriam utilizados na montagem da composteira doméstica feita com garrafa pet. Depois dessa aula, compartilhei alguns modelos via e-mail para as turmas, com orientações de montagem e dos materiais necessários e combinamos de levar cascas de frutas e ou verduras para a oficina de composteira, que aconteceu em momentos e turmas diferentes, criando espaços de convivência e de aprendizagens.

Em seguida, organizamos a sala de aula para a oficina de composteira ao som de algumas canções e a exibição do vídeo "A Natureza está Falando: o solo", narrado na voz do cantor e compositor brasileiro Gilberto Gil, produzido por uma organização brasileira sem fins lucrativos “Conservação Internacional” (CONSERVAÇÃO..., 2015). A sala cheirava a terra e na mesa foram expostos os materiais: estilete, tesoura, prego para furar a tampa da garrafa, pedrinhas, terra para plantio e cascas de frutas e verduras. Gestos, brincadeiras, conversas, músicas, um vai e vem constante povoando a sala por completo. Quem terminava a montagem auxiliava os outros. Após a oficina, exercitamos um diálogo amoroso, aguçado pela curiosidade sobre o artefato montado e suas possibilidades éticas, políticas e pedagógicas, relacionando-o com as dimensões ecológicas, culturais e econômicas.

Gostei da ideia, professor, minha avó vai gostar. Dá pra fazer essa composteira com as séries iniciais, pedindo a ajuda dos familiares no preparo da estrutura. É uma boa oportunidade para estudarmos os solos e nossos hábitos alimentares.

Esse contato com a terra...adorei a ideia. Eu também fiquei pensando nos hábitos alimentares que temos em casa. Mais do que a montagem da composteira, o legal é que a gente vai lembrando dessas coisas. Lembrei da minha infância. E fiquei pensando na fragilidade do solo e de como a gente não tem esse cuidado com o que comemos, e nem sabemos se o que comemos tem agrotóxico ou se é transgênico.

Professor, de acordo com o texto é possível realizarmos práticas ecologistas de educação e com a composteira é possível a gente discutir na escola a agricultura orgânica e a agroecologia.

Eu gostei muito da oficina, vou propor para a professora do estágio e tentar fazer lá na escola. Lembrei que eu assisti esses vídeos citados no artigo quando estava no ensino médio.

Compartilhamos memórias, saberes, dúvidas e curiosidades de como cuidar da composteira, o que deve e não deve pôr, onde guardar, os processos de decomposição, os perfis e tipos de solos, processos de erosão, código florestal, desmatamentos. As curiosidades e problematizações não pouparam também os nefastos modelos de agroindústria e o "agro é pop", e seus impactos na agricultura familiar e na agroecologia. Com a oficina de composteira 
dialogamos sobre as contribuições pedagógicas, políticas e ecologistas para os cotidianos escolares, sem classificações etárias e disciplinares, por entendermos que as problemáticas germinadas com a composteira estão diretamente relacionadas com nossas vidas cotidianas.

Os diálogos de saberes com a oficina de composteira possibilitaram intensas reflexões acerca das problemáticas ecológicas na saúde humana e de animais domésticos, decorrentes dos consumos de alimentos transgênicos, inclusive as questões que envolvem os "T's" nas embalagens dos alimentos, os agrotóxicos, fertilizantes e alimentos industrializados, a Revolução Verde, as "bancadas" ruralistas e o "pacote de veneno", as monoculturas, a segurança alimentar e o equilíbrio ecológico, os tipos de solos do Brasil, e, as relações entre os hábitos alimentares dos povos indígenas e das comunidades quilombolas e suas influências em nossos hábitos alimentares "modernos" e urbanos.

Com as oficinas de composteira fertilizamos nas turmas diálogos amorosos, alimentados pelas dimensões éticas, políticas, pedagógicas e ecologistas de educação, com situações reais e concretas, que envolvem nossos hábitos alimentares, de consumo e de relações com os solos e as condições de vida de milhares de trabalhadoras e trabalhadores rurais. Contribuindo para que essas problemáticas adentrem os territórios de aprendizagens aproximando os cotidianos escolares e os espaços de formação, deslocando nossa curiosidade ingênua para a curiosidade epistemológica, pois, "quanto mais criticamente se exerça a capacidade de aprender, tanto mais se constrói e desenvolve o que venho chamando "curiosidade epistemológica", sem a qual não alcançamos conhecimento cabal do objeto" (FREIRE, 1996, p. 24-25). 


\section{Aula de Campo}

Como experiência especificamente humana, a educação é uma forma de intervenção no mundo (FREIRE, 1996, p. 98).

Figura 1 - Praça Costa Pereira

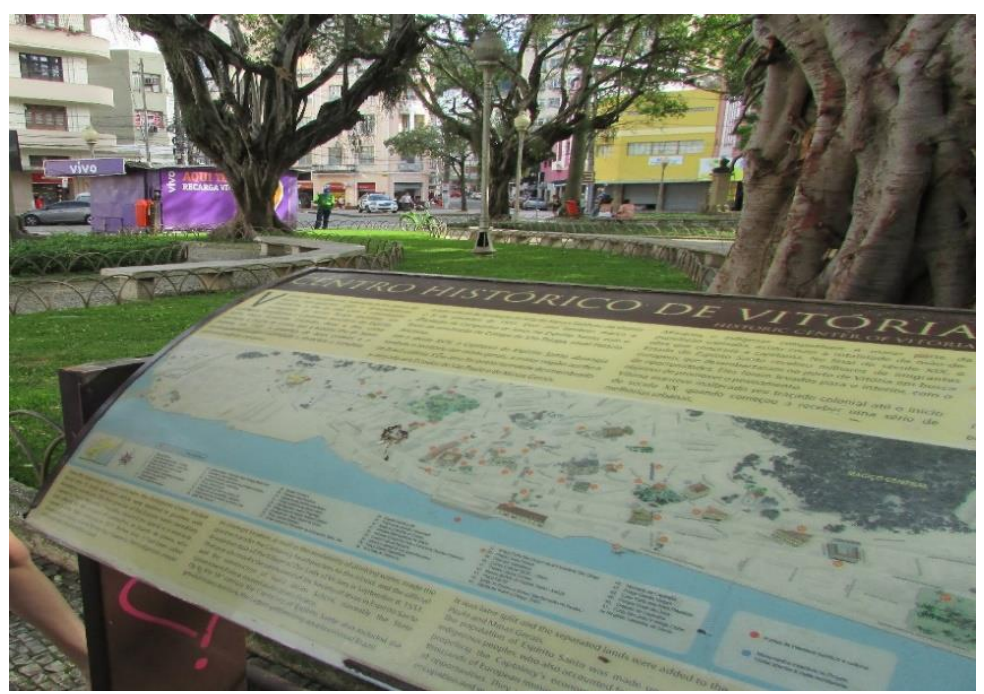

Fonte: Arquivo pessoal dos autores

Os movimentos aqui apresentados foram desencadeados em conversas e experiências com a paisagem, com o que ela te provoca a pensar, das narrativas possíveis de um mesmo lugar tornando-o múltiplo e dinâmico. Durante as aulas e com as leituras e diálogos com os artigos indicados no início deste texto, aproveitamos o momento para apresentarmos outras publicações, dentre elas os livros "Centro de Vitória" (DADALTO, 1999), "Atlas ambiental de Vitória, ES" (ATLAS, 2013), "Marcovaldo e os doze passeios em Vitória: percursos temporais de conhecimento e valorização da região central da cidade" (KUSTER, 2003), e "Passeio pelo centro de Vitória na companhia de Rubem Braga” (NEVES, 1992).

Nestes encontros compartilhamos narrativas e "experiências das/nas paisagens" (GUIMARÃES et al, 2015), e, novamente, de repente, um graduando comenta sobre o centro histórico de Vitória, relembrando das suas experiências quando atuou num projeto voltado para a recepção de visitantes nos monumentos históricos da chamada "cidade alta", destacando e fazendo coro com as leituras e problematizações em sala de aula, ao dizer que se trata de um lugar conhecido pelas narrativas sobre o lugar, definidas pelo ponto de vista dos colonizadores. 
A partir deste diálogo surgiu a ideia de fazermos uma Aula de Campo no centro histórico de Vitória. Proposta foi aceita pela turma e ampliamos a possibilidade de envolver as outras turmas da graduação, possibilitando a criação de encontros e integração acadêmica entre estudantes com as paisagens e com outras geografias.

E assim chegou o dia da Aula de Campo com os estudantes dos cursos de graduação em Geografia e Pedagogia. Os grupos foram se encontrando e se conhecendo em diálogos amorosos, compartilhando curiosidades, aprendizagens, estranhamentos e descolamentos com o lugar, com a paisagem e consigo mesmos. Encontros com as diferentes formas que a cidade se apresenta aos nossos olhares e corpos, que nos atravessam com seus sons, cores, cheiros, memórias e emoções.

Figura 2 - Praça Costa Pereira

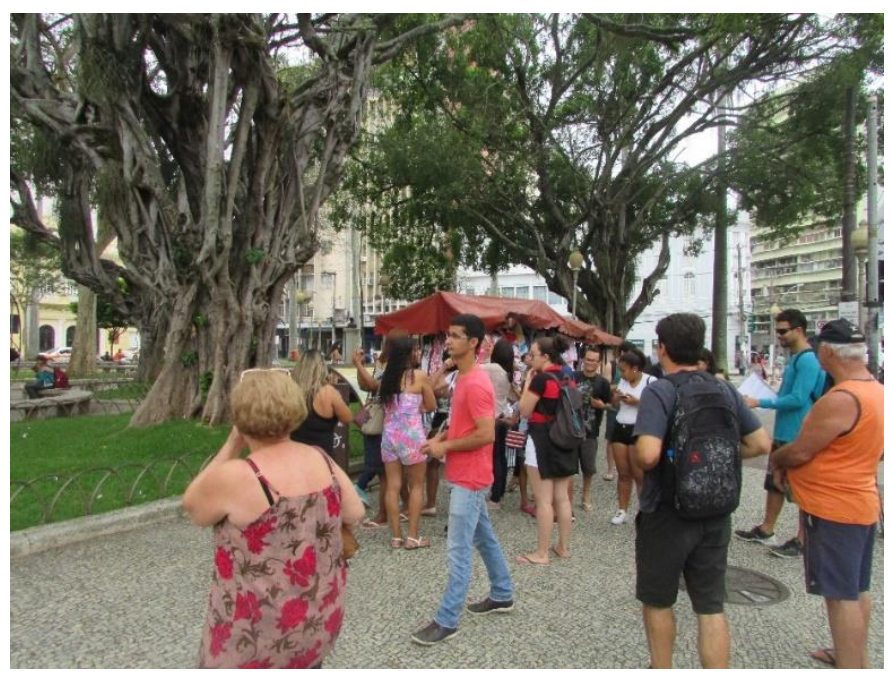

Fonte: Arquivo pessoal dos autores

Com essa experiência foi possível sentir forças invisíveis nos encontros com as construções coloniais e modernas, ruas retas, sinuosas, íngremes, ladrilhos, ladeiras, asfalto e escadarias a serem percorridas, rasurando o mapa da cidade que habita em nós, trazendo a tona outras geografias, com "paisagens sensacionais" (RIBEIRO, 2015), preenchidas com detalhes, silhuetas, gestos, desvios, emoções e descobertas.

Era uma bonita manhã de sábado. Combinamos de nos encontrar na Praça Costa Pereira e de terminarmos o percurso - ainda desconhecido - na barraquinha de pastel e de caldo de cana, na tradicional feira livre da Rua Sete de Setembro. O início e o fim era o que sabíamos. Teríamos que fazer os percursos para sabermos o que encontraríamos no caminho. A Praça Costa Pereira 
abrigava várias pessoas em situação de rua, "os humilhados do parque com os seus jornais", retratados na canção "Alucinação", de Belchior (1976). Mapeamos a paisagem com os olhos e com o corpo em toda a sua extensão. Estávamos em 38 pessoas que, de repente, todas e todos se veem diante de uma faixa no chão pintada de azul.

O que essa faixa indica professor?" - perguntou um graduando da Geografia.

Essa faixa azul no chão percorre um trecho da cidade baixa, representando o nível do mar na época da colonização. Fiquei sabendo disso por que sou moradora daqui do centro. No passado a Costa Pereira era uma praia, a prainha, com uma igreja de Nossa Senhora da Conceição, que ficava onde hoje foi construído o Teatro Carlos Gomes." - respondeu uma graduanda da Pedagogia.

Na placa turística tá mostrando que tinha também um lago artificial na praça, onde estão os bancos e jardins, que hoje servem de abrigo para as famílias e pessoas em situação de rua. É difícil imaginar que tudo isso já foi banhado pelo mar e que já teve um lago artificial e um chafariz aqui, e que o bondinho passava aqui também.

Eu conheci a Costa Pereira quando participava dos atos políticos e das manifestações culturais.

Quanto tempo que não venho aqui. Lembro de quando era criança. A gente comia pastel com caldo de cana ali, no Garapa da Cidade.

Só hoje que eu fui perceber aquela escultura de ferro ali. Fui lá ver o nome dela. Se chama "Mãe".

Figura 3 - Rua Sete de setembro

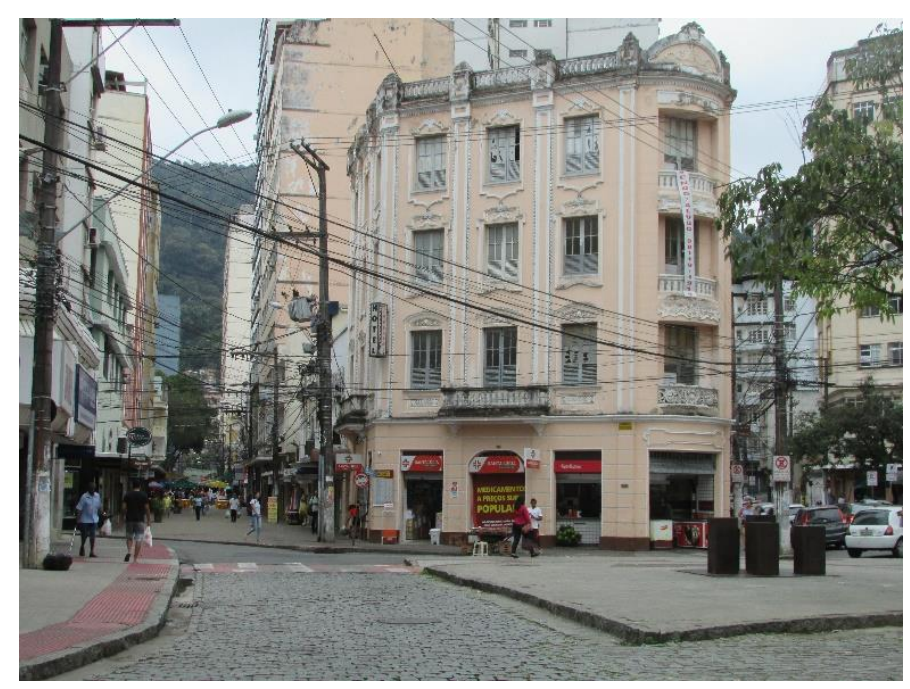

Fonte: Arquivo pessoal dos autores

Continuamos a caminhar em busca de "um modo de ver a mais", criando estranhamentos, diálogos e narrativas, aprendendo com as paisagens do lugar. Para chegarmos na "cidade alta" e na Catedral Metropolitana, optamos pelo acesso da Escadaria São Diogo, de estilo eclético e que 
no período colonial era conhecida como Ladeira da Pedra e construída ao lado de um forte. Em frente à escadaria nos deparamos com esculturas metálicas que chamaram nossa atenção: trata-se de um memorial em homenagem aos desaparecidos políticos, durante a época do regime civilmilitar no Brasil. Memórias de seis dos principais personagens capixabas, que participaram da Guerrilha do Araguaia, no início da década de 70.

Depois de tantas descobertas e ainda no início do percurso, subimos a escadaria e chegamos à Catedral Metropolitana de Vitória, que em 1551 era uma pequena igreja de estilo colonial, na época que Vitória se chamava Vila Nova. O projeto atual da catedral precisou de 50 anos para ser construído e contém uma decoração com grandes vitrais coloridos e uma arquitetura eclética e neogótica. Vista de cima, a catedral tem um formato de uma cruz.

Ao lado da catedral nos deparamos com a Escadaria Maria Ortiz. O encontro com a escadaria possibilitou que conhecêssemos sua história. No período colonial era conhecida como Ladeira do Pelourinho, tendo sido também o palco de uma batalha contra as invasões de piratas holandeses em 1625.

O nome da escadaria é em homenagem à jovem Maria Ortiz, que, aos 22 anos, combateu a invasão de piratas holandeses que tentaram conquistar a ilha de Vitória. A jovem Maria Ortiz incentivou os vizinhos a arremessarem água fervente, brasas e pedra sobre os piratas invasores, que se viram encurralados, desistindo da invasão. Em 1899 a ladeira recebeu o nome de Maria Ortiz, e, em 15 de novembro de 1924, foi inaugurada com o nome de Escadaria Maria Ortiz.

Professor, quer dizer que se não fosse a Maria Ortiz, a gente poderia ter sido colônia holandesa? - Esse questionamento gerou um murmurinho entre o grupo.

Ela foi uma mulher corajosa que não se deixou colonizar. - Comentou uma estudante.

Andarilhando por alguns pontos conhecidos do centro histórico, conversamos com a paisagem, aprendemos com ela, conhecemos e dialogamos com a história, em busca de outras narrativas, versões, casos, acontecimentos, personalidades, lançando nossos olhares e corpos para as intervenções, ocupações, mobilidades, conflitos e diferentes usos dos espaços públicos da urbe, rasurando os lugares, com o desejo de percorrer, sentir e ouvir narrativas outras, que narram outra cidade, cidades dentro da cidade.

Continuamos nossas conversas com a paisagem e a cidade ouvindo o que elas nos diziam, gritavam ou silenciavam, percebendo como elas nos acenavam e o que estava contido nelas. 
Estávamos em busca de outras paisagens, cartografias e geografias que não cabem em mapas convencionais e em narrativas oficiais e acadêmicas. Ouvimos, sentimos e percorremos a cidade com a atenção aberta e distraída, e fomos afetados por outras cidades, diferente daquela cidade indicada nas narrativas e mapas das placas dos pontos turísticos do centro histórico de Vitória.

Com esses encontros percorremos territórios sonoros, afetivos, gustativos, cromáticos, sombrios, olfativos, nos aproximamos de outras geografias e narratividades com a paisagem e suas intervenções estéticas, monumentos, igrejas, escadarias, praças, jardins, os traçados coloniais de suas ruas, ladeiras, museus, conventos, detalhes nas arquiteturas, pichações, grafites, esconderijos, bocas de fumos e hortas. Hortas?!

Figura 4 - Vista para a Catedral Metropolitana de Vitória

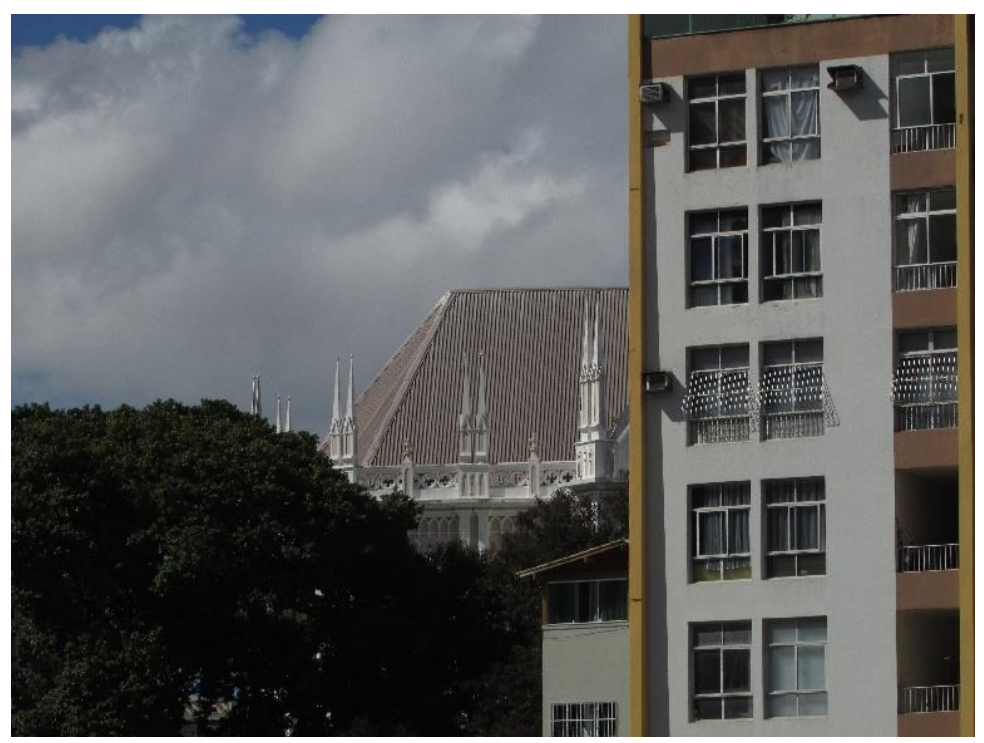

Fonte: Arquivo pessoal dos autores 
Figura 5 - Escadaria Maria Ortiz

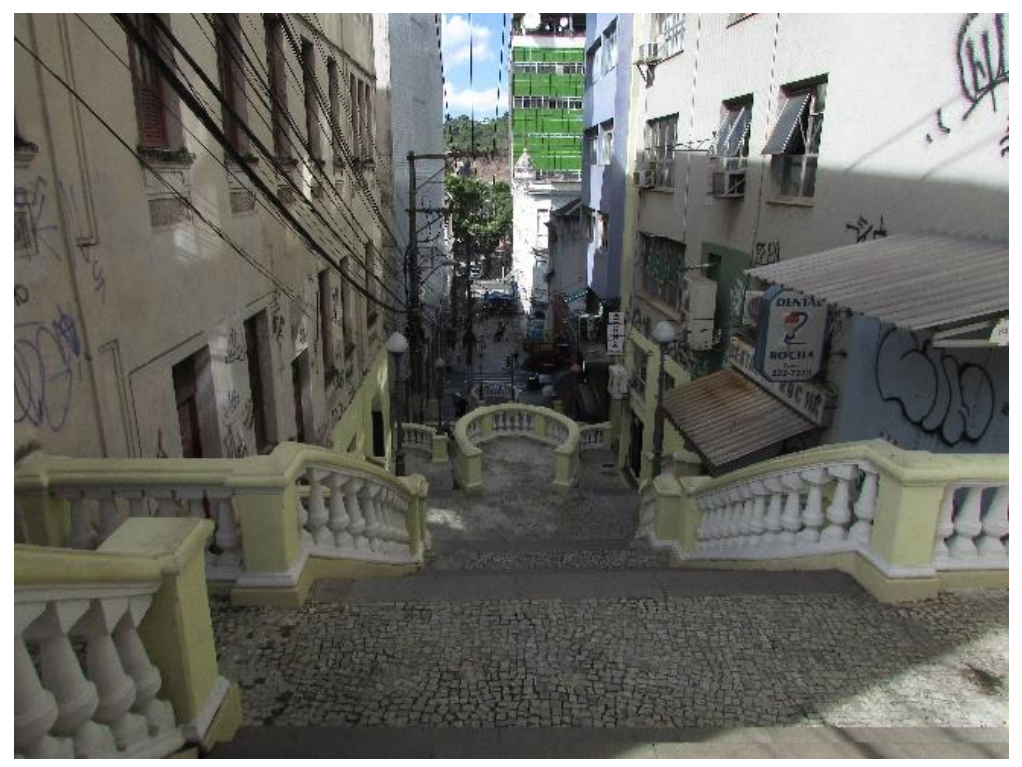

Fonte: Arquivo pessoal dos autores

\section{Quintal da cidade}

Como professor devo saber que sem a curiosidade que me move, que me inquieta, que me insere na busca, não aprendo nem ensino. Exercer a minha curiosidade de forma correta é um direito que tenho como gente e a que corresponde o dever de lutar por ele, o direito à curiosidade (FREIRE, 1996, p. 85).

\section{Figura 6 - Horta Comunitária "Quintal na Cidade"}

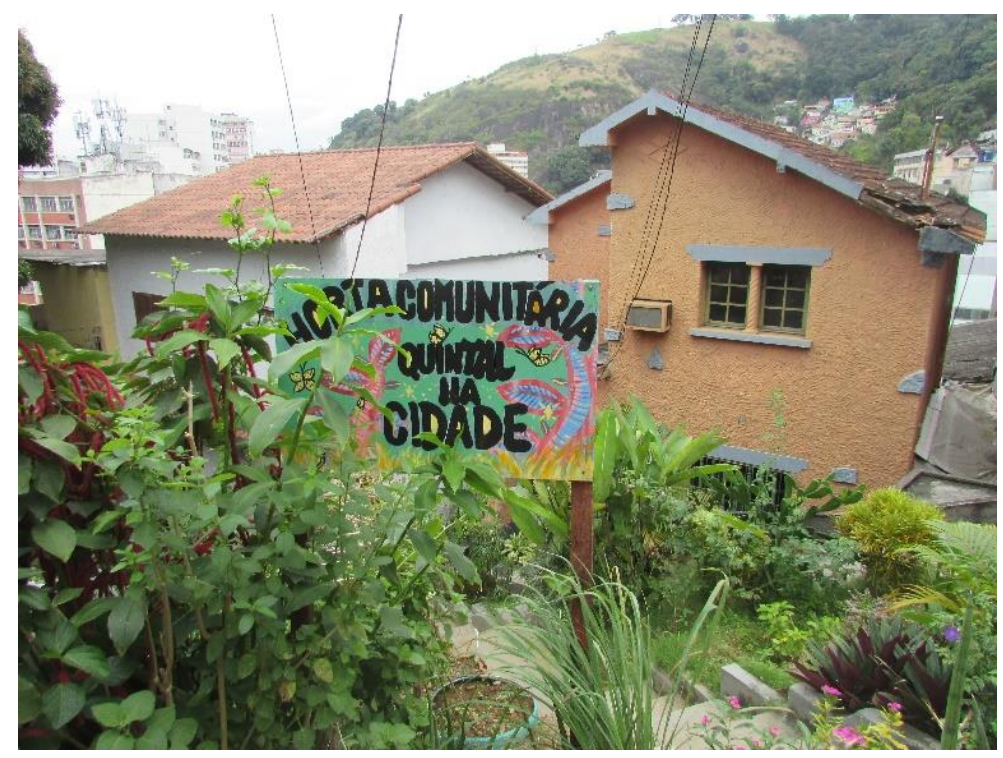

Fonte: Arquivo pessoal dos autores 
Continuamos as travessias e conversas com a paisagem e a cidade, e chegamos no Viaduto Caramuru, construído em 1925 para a passagem do bonde que circulava na cidade alta. Entretanto o bonde nunca passou pelo viaduto, devido à suspeita de que não aguentaria o seu peso e de que o bonde não seria capaz de fazer a curva que liga as duas ruas. Abaixo do viaduto está a Rua Caramuru, palco de uma batalha contra holandeses que tentaram invadir a ilha em 1640.

Essa mesma curva nos levou ao encontro de um morador local, que estava passeando com o seu cachorro e nos indagou pensando que fôssemos da campanha de vacinação. Quando soube que éramos da Ufes, dos cursos de Pedagogia e Geografia, perguntou ao grupo: "Vocês conhecem a horta comunitária que cuidamos aqui perto?".

Ficamos curiosos em conhecer essa horta comunitária e fomos conferir de perto. A horta fica atrás do muro do Convento de São Francisco, numa rua sem saída, que estava abandonada e era usada como depósito de lixo. Na entrada encontramos uma placa nos informando que ali era uma "ocupação" chamada de "Quintal na cidade". No muro dos fundos do Convento avistamos os escritos "Ocupa verde" e "Bora plantar! Verdeja".

Figura 6 - Horta Comunitária "Quintal na Cidade"

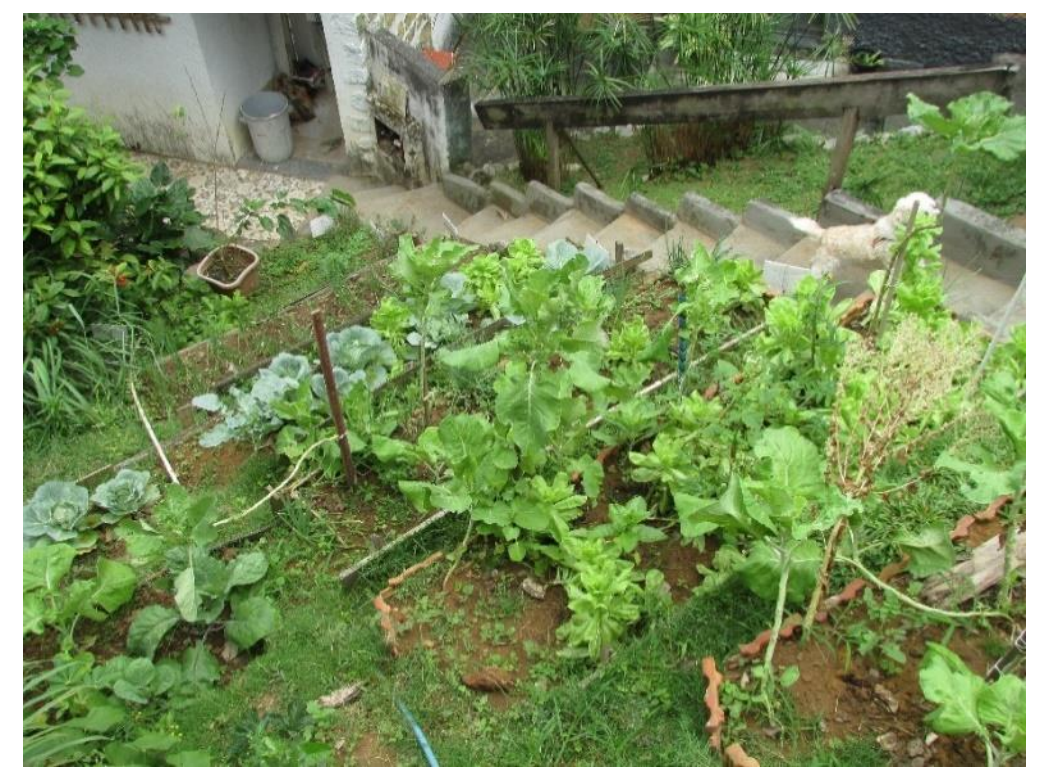

Fonte: Arquivo pessoal dos autores 
Estou me sentido como se estivesse na casa da minha mãe, lá na roça, só que estou no centro da cidade. Nunca imaginei isso [...]. Aquilo ali é o quê? Aquela geladeira? Quem ajuda aqui na horta? A prefeitura ajuda também?

É uma biblioteca comunitária, batizada de "Hortoteca". Essa é uma horta comunitária e orgânica cuidada voluntariamente por 12 famílias, que cultivam hortaliças, plantas medicinais, bananas, temperos. Trabalhamos na forma de mutirão desde 2014, quando eu vim morar aqui.

E a horta está produzindo?

Olha, ela produz isso aqui que você está fazendo agora, por exemplo. Interagindo com o alimento. A gente está muito distante disso. Tem família que traz a criança aqui para ter essa experiência. Mas a horta vive de doações também...Hoje, como podem ver, temos uma composteira, minhocário e uma geladeira, que foi adaptada para ser uma biblioteca comunitária.

E tem escola que visita?

Tem sim [...] o pessoal já visitou. Essa semana vai ter um grupo da Geografia da Ufes e da Arquitetura, que está com a ideia de fazer um mirante nessa árvore cortada.

Ocupamos o espaço da horta comunitária e desfrutamos da vista para os morros e o porto de Vitória. Atualmente a horta recebe visitantes, curiosos e grupos de estudantes. Quinzenalmente o "Quintal da cidade" é cuidado por voluntários que exercitam uma ação solidária e ecológica na comunidade. Os canteiros da horta, assim como a cidade alta, seguem a declividade do terreno, criando um ambiente acolhedor e com cheiro de terra molhada, com flores diversas e uma árvore no centro do terreno. Numa das laterais do terreno encontramos a residência de nosso anfitrião, que nos colocou em contato com plantas medicinais: cidreiras, hortelãs, boldos, alecrins, manjericões verde e roxo, babosas, arrudas e melissas.

Encontramos também bananeiras, pimentas, acerola, pitanga, jabuticabas, goiabas e outras árvores frutíferas, além de temperos, verduras e hortaliças, couve, salsa, coentro, mostarda, orégano, rúcula, milho, mandioca. Deparamo-nos com composteiras, sementeiras, mudas, minhocário e uma "hortoteca", nome dado a uma geladeira transformada em biblioteca comunitária.

Foi um prazeroso, inusitado e bonito encontro. Ficamos fascinados com o lugar. Nossos olhares e corpos, antes ruas e concreto, agora, uma horta comunitária, num lugar totalmente desconhecido. Os canteiros sinuosos que aguçaram nossas curiosidades em apalpar, agachar para ver de perto, cheirar, provar e degustar. 
Aqui é um lugar perfeito para interagir com o solo. Repensar o que estamos fazendo com o solo. Solo é vida e a gente nem percebe. Esse lugar faz isso com a gente.

Dá também para ver uma proposta de agroecologia e de alimentação saudável. Lembrei da oficina de composteira, professor!

É mesmo. A composteira...tem uma ali. Aqui é um lugar bom para gente refletir sobre nossos hábitos alimentares e dos alimentos que consumimos.

E dos que a gente está deixando de consumir. Tem coisa que a gente nem conhece. Só ouve falar. Nunca nem viu.

E isso tem relação com o agronegócio, a revolução verde, agrotóxicos, e agora, os transgênicos e o "pacote do veneno". Aquilo que conversamos em sala de aula, não é professor?!

Fazendo uma relação também com a política. Lembrando da bancada ruralista e da política agrícola do nosso país.

Com a ocupação da horta comunitária a conversa se fertilizou e alimentou as possibilidades pedagógicas e ecológicas. E isso fez com que os estudantes, que estavam nessa aula de campo e que haviam participado da oficina de composteira, feita com garrafas pet em uma aula da Ufes, relembrassem da oficina e do artigo do professor Rodrigo Barchi. Discutimos situações reais que estão em nossa vida cotidiana, em relação ao solo, à alimentação, à saúde e à vida, e que entram sem pedir licença, atravessando limites e fronteiras disciplinares e curriculares.

Figura 7 - Vista para Morro da cidade de Vitória

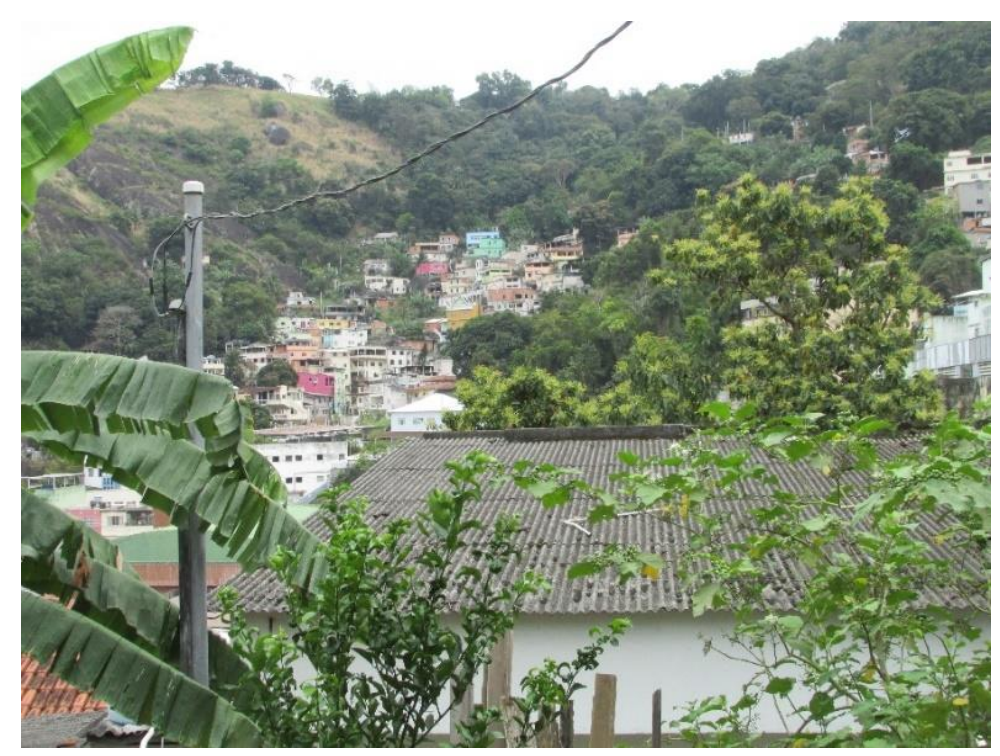

Fonte: Arquivo pessoal dos autores 


\section{Encontros na sala de aula}

O mundo não é. O mundo está sendo (FREIRE, 1996, p. 76).

Os encontros com a horta comunitária suscitaram relações de aprendizagens e diálogos amorosos, provocando também memórias dos movimentos que aconteceram com as oficinas de composteira em sala de aula, realizadas com as turmas.

Após os desdobramentos e movimentos das Aulas de campo, Oficinas de Composteira e das experimentações e aprendizagens com as paisagens e as cidades, lançamos a proposta dos estudantes se organizarem em Grupos de Trabalhos (GTs), para cartografar e apresentar as experiências e vivências que tiveram na aula de campo. A prática pedagógica consistia em cartografarem as diferentes narrativas e experimentações que vivenciaram com as paisagens e com a cidade.

Os GTs prepararam mapas, croquis ou "mapas sensacionais” que continham inumeráveis espacialidades, territorialidades, temporalidades, repletos de detalhes singulares de cada grupo, incluindo desenhos, linhas, símbolos e fotografias, trazendo aos mapas vividos e inventivos, as relações entre o moderno e o antigo, as ecologias, ocupações, mobilidades urbanas, comércios, conflitos e desigualdades sociais, intervenções urbanas, cores, cheiros, relações humanas, gestos, afetos, na escala da vida cotidiana.

Cada GT destacou cartografias outras e com nomes criativos: "Passos por Vitória”, “Onde a cartografia e o sentimento se encontram", "Nossos olhares no centro de Vitória", "Centro histórico de Vitória", "Tesouros de Vitória", "Mapa mental: registro da aula de campo", "Mapa mental: centro de Vitória". Outros mapas eram nomeados como "Mapa mental”, e há ainda, os que não tinham títulos, abertos em sua radicalidade inventiva.

As apresentações dos mapas foram acompanhadas pela exibição de um pequeno vídeo de até 4 minutos, reunindo imagens, fotografias, gestos, detalhes, paisagens e "um ver a mais" do centro histórico de Vitória embalado por canções escolhidas por cada GT. Os vídeos foram elaborados de modo coletivo e solidário pelos grupos de estudantes, que foram orientados a criarem outras narrativas, cartografias e geografias da cidade, com outras formas representativas do espaço e que levassem em consideração as intensidades, os processos que emergiram nos encontros com a cidade e com a paisagem, subvertendo as representações hegemônicas das 
cartografias cartesianas. As exibições dos vídeos e mapas foram encharcadas de imagens afetivas, ecologistas e dialógicas, enaltecendo com alegria e boniteza as aprendizagens e as outras geografias vividas com as práticas pedagógicas ecologistas que realizamos.

Com a elaboração dos mapas, os GTs apresentaram suas cartografias e geografias afetivas com legendas e símbolos criativos. Os grupos criaram mapas de diferentes tamanhos, texturas, materiais e com objetos acoplados. Todos com muitas cores, alguns com colagens de figuras, traços intensivos, gestos, emoções, desenhos e fotografias da aula de campo. Nas cartografias e geografias afetivas criaram mundos e outras ecologias e modos de narrar a cidade e suas histórias, nos fazendo aprender com a história, com lugares dentro do lugar, produzindo outras narrativas com a paisagem, outras geografias, espaços e territórios.

Figura 8 - Mapas produzidos pelos Grupos de Trabalhos

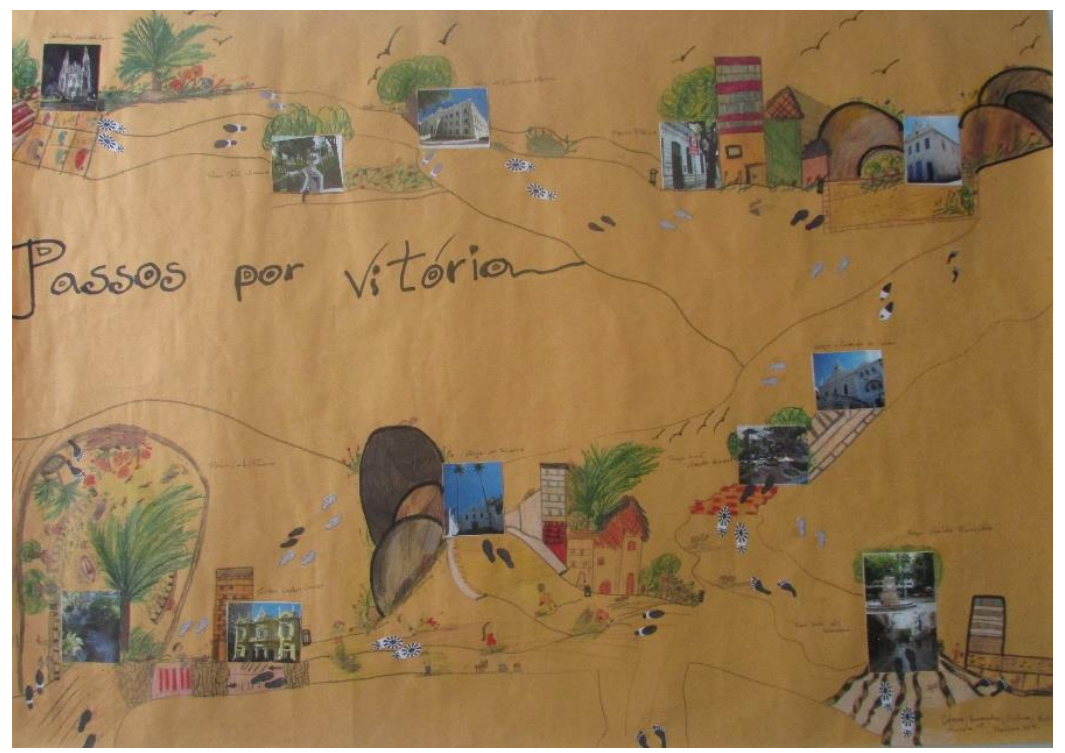

Fonte: Arquivo pessoal dos autores 
Figura 9 - Mapas produzidos pelos Grupos de Trabalhos

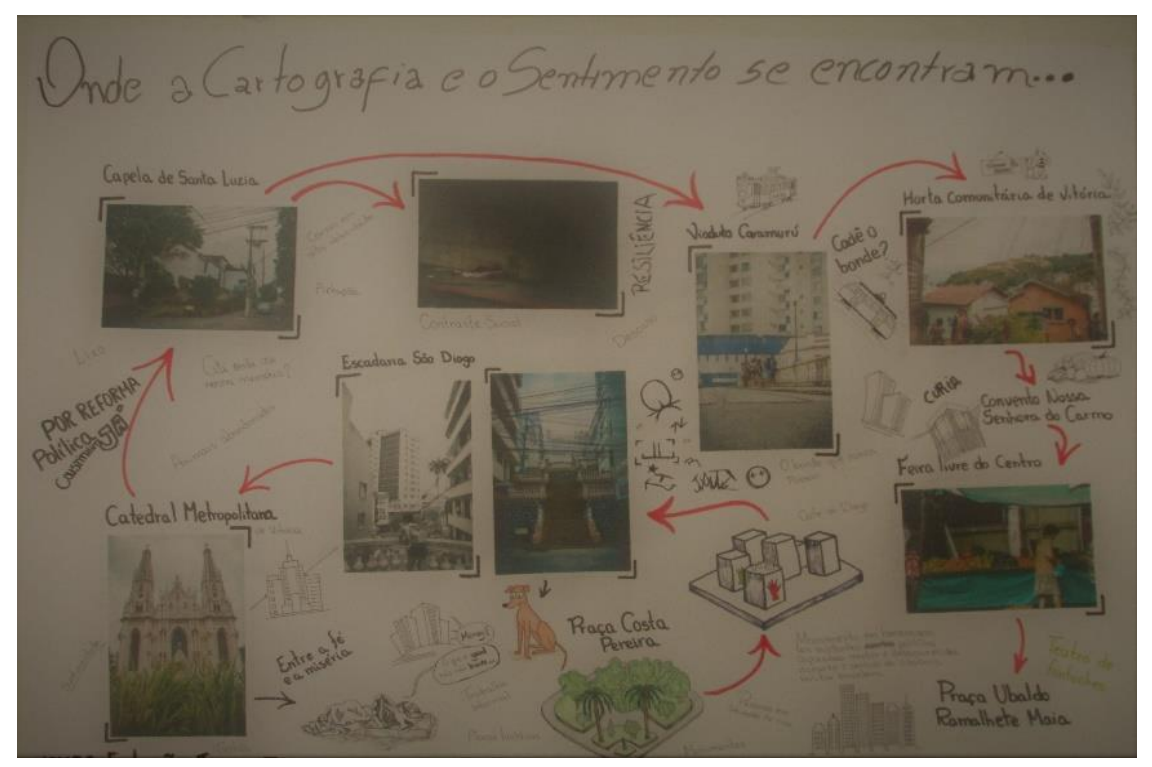

Fonte: Arquivo pessoal dos autores

\section{Continuando os caminhos}

Mudar é difícil. Mas é possível (FREIRE, 1996, p. 79).

E assim chegamos à (in)conclusão deste texto, que nos trouxe algumas pistas e aproximações com as perspectivas ecologistas de educação, levando-nos a exercitar em nosso fazer docente posicionamentos éticos, políticos e metodológicos, com práticas pedagógicas envolvendo estudantes dos cursos de Pedagogia e Geografia da Ufes. Acreditamos nos diálogos amorosos e numa educação libertadora, em que educadores e educandos, simultaneamente, se façam educadores e educandos, com práticas pedagógicas problematizadoras, sendo que "ninguém educa ninguém, ninguém educa a si mesmo: os homens e "as mulheres" se educam em comunhão, mediatizados pelo mundo" (FREIRE, 2014, p. 96).

Portanto, "a educação problematizadora se faz com um esforço permanente através do qual os homens e "as mulheres" vão se percebendo, criticamente, como estão sendo no mundo" (FREIRE, 2014, p. 100), pois:

Mulheres e homens, seres históricos-sociais, nos tornamos capazes de comparar, de valorar, de intervir, de escolher, de decidir, de romper, por tudo isso nos fizemos seres éticos. Só somos porque estamos sendo. Estar sendo é uma condição, entre nós, para ser. (FREIRE, 1996, p. 33). 
Com esses movimentos de estar sendo, "como um ser inconcluso, consciente de sua inconclusão" (FREIRE, 2014, p. 101), que percorremos territórios nos processos de ensinar e aprender, com as práticas pedagógicas, que aqui denominamos ecologistas e que foram apresentadas neste texto. Essas práticas potencializam outros modos de agir, intervir, de aprender e ensinar com, e, no mundo, pois "não há docência sem discência, as duas se explicam e seus sujeitos apesar das diferenças que os conotam, não se reduzem à condição de objeto, um do outro. Quem ensina aprende ao ensinar e quem aprende ensina ao aprender" (FREIRE, 1996, p. 23).

\section{Referências}

ATLAS ambiental: Vitória, ES, Brasil. São Paulo: Geodinâmica, 2013.

BELCHIOR, Antônio Carlos. Alucinação. Rio de Janeiro: Philips/Phonogram, 1976. Disponível em: https://www.youtube.com/watch?v=9K3Wj5BZBF4\&list=RD9K3Wj5BZBF4\&start_radio $=1 \& \mathrm{t}=0$. Acesso em: 27 mar. 2019.

BARCHI, Rodrigo. As perspectivas ecologistas em Educação e as hortas pedagógicas e orgânicas: a ação do PIBID Geografia da UNISO. Crítica Educativa, Sorocaba, v. 3, n. 2, Especial, p. 799-817, jan./jun. 2017.

BARCHI, Rodrigo; REIGOTA, Marcos; YANG, Andre Luiz Chaves. Ecosofia tropical, educação ambiental canibal e a aventura de desnudar-se. Linha Mestra, Campinas, n. 35, p. 265-277, maio/ago. 2018.

CONSERVAÇÃO INTERNACIONAL. A natureza está falando: Gilberto Gil é o solo. 2015. Disponível em: https://www.conservation.org/global/brasil/Pages/solo.aspx. Acesso em: 14 dez. 2018.

DADALTO, Maria Cristina. Centro de Vitória. Vitória: Secretaria Municipal de Cultura, 1999.

FIRMINO, Larrisa Corrêa. Cidade, lugar do possível: experimentações para um ver a mais.

Textura, Canoas, n. 30, p. 72-85, jan./abr. 2014.

FIRMINO, Larrisa Corrêa. Imagem e clichê: proposições para um ver a mais. In:

GUIMARÃES, Leandro Belinaso et al. (orgs.). Ecologias inventivas: experiências das/nas paisagens. Curitiba: CRV, 2015. P. 187-196.

FREIRE, Paulo. Pedagogia da autonomia: saberes necessários à prática educativa. São Paulo: Paz e Terra, 1996.

FREIRE, Paulo. Pedagogia do oprimido. 58. ed. São Paulo: Paz e Terra, 2014. 
FREIRE, Paulo; GUIMARÃES, Sergio. Aprendendo com a própria história. São Paulo: Paz e Terra, 2011a.

FREIRE, Paulo; GUIMARÃES, Sergio. Dialogando com a própria história. São Paulo: Paz e Terra, 2011b.

GUIMARÃES, Leandro Belinaso. Como escrever com os ruídos do mundo? In: CHAVEZ, Silvia; BRITO, Maria dos Remédios de (orgs.). Formação, ciência e arte: autobiografia, arte e ciência na docência. São Paulo: Livraria da Física, 2016. p. 89-102. Disponível em: http://www.academia.edu/31279982/Como_escrever_com_os_ru\%C3\%ADdos_do_mundo. Acesso em: 2 ago. 2018.

GUIMARÃES, Leandro Belinaso et al. (orgs.). Ecologias inventivas: experiências das/nas paisagens. Curitiba: CRV, 2015.

KUSTER, Eliana. Marcovaldo e os doze passeios em Vitória: percursos temporais de conhecimento e valorização da região central da cidade. Vitória: [s. n.], 2003.

NEVES, Luiz Guilherme Santos. Passeio pelo centro de Vitória na companhia de Rubem Braga. São Paulo: Empresa das Artes. 1992.

PREVE, Ana Maria Hoepers et. al. Ecologias inventivas: conversas sobre educação. Santa Cruz do Sul, RS: EDUNISC, 2012.

RAMOS, Andreia Teixeira. Mulheres no congo do Espírito Santo: práticas de re-existência ecologista com os cotidianos escolares. 2018. Tese (Doutorado em Educação) - Universidade de Sorocaba, Sorocaba, 2018.

REIGOTA, Marcos. Meio ambiente e representação social. 3. ed. São Paulo: Cortez, 1998.

REIGOTA, Marcos. Ecologistas. Santa Cruz do Sul: Edunisc, 1999a.

REIGOTA, Marcos. Ecologia, elites e intelligentsia na América Latina: um estudo de suas representações sociais. São Paulo: Annablume, 1999b.

REIGOTA, Marcos. O que é educação ambiental. São Paulo: Brasiliense, 2012. (Coleção Primeiros Passos; 292).

REIGOTA, Marcos. Aspectos teóricos e políticos das narrativas: ensaio pautado em um projeto transnacional. In: CORDEIRO, R.; KIND, L. (orgs.). Narrativas, gênero e política. Curitiba: CRV, 2016.

RIBEIRO, Danilo Stank; DESIDÉRIO, Raphaela; PREVE, Ana Maria H. Geografia experimental do corpo ou de como se chega a dizer outra coisa da geografia, da terra, do mundo. Linha Mestra, Campinas, n. 23, p. 12-19, ago./dez. 2013. 
RIBEIRO, Danilo Stank. Paisageando na composição de paisagens sensacionais. In:

SEMINÁRIO INTERNACIONAL DE FILOSOFIA, POÉTICA E EDUCAÇÃO, 2.; 2015, Juiz de Fora. Juiz de Fora, MG. Anais [...]. Juiz de Fora, MG, Universidade Federal de Juiz de Fora, 2015. Disponível em: https://sifpe.files.wordpress.com/2015/10/danilo-stank-ribeiropaisageando-na-composic3a7c3a3o-de-paisagens-sensacionais.pdf. Acesso em: 2 ago. 2018.

SPINK, Peter. Kevin. O pesquisador conversador no cotidiano. Psicologia \& Sociedade, São Paulo, v. 20, edição especial, p. 70-77, 2008. 